\title{
Prática diária dos agentes comunitários de saúde: dificuldades e limitações da assistência
}

\author{
Daily practice of community health agents: difficulties and limitations of care
}

Práctica diaria de los agentes comunitarios de salud: dificultades y limitaciones de la asistencia

\author{
Marilisa Baralhas', Maria Alice Ornellas Pereira" \\ ' Universidade do Grande ABC, Curso de Graduação em Enfermagem. Santo André-SP, Brasil. \\ "Universidade Estadual Paulista "Júlio de Mesquita Filho", Faculdade de Medicina de Botucatu, Departamento de \\ Enfermagem. Botucatu-SP, Brasil.
}

\author{
Submissão: 08-04-2011 Aprovação: 24-04-2013
}

\section{RESUMO}

O presente estudo, de natureza qualitativa, objetivou conhecer as dificuldades sentidas pelos Agentes Comunitários de Saúde (ACS) no exercício da prática diária da assistência. Os dados foram coletados por meio de entrevista semiestruturada com doze ACS de quatro Unidades Básicas de Saúde de um município do estado de São Paulo. A partir dos discursos dos sujeitos, constatou-se que a carência de ações resolutivas nos serviços de saúde, a sobrecarga do enfermeiro responsável pela equipe e a rejeição dos usuários ao atendimento são fatores que dificultam a execução das ações de saúde. Essa pesquisa enfatiza as limitações manifestadas pelos participantes e aponta a importância de exploração dessa temática, buscando estratégias capazes de possibilitar a consolidação dos princípios do SUS.

Descritores: Atenção Primária à Saúde; Serviços de Saúde Comunitária; Assistência à Saúde.

\begin{abstract}
This qualitative study aimed to identify difficulties experienced by Community Health Agents (CHA) in the course of daily practice of care. Data were collected from semi-structured interviews with twelve CHA from four Basic Health Units in a city of the state of São Paulo, Brazil. From an analysis of the speech of subjects, we found that the deficiency of health services, the workload of the nurses responsible for the team and the service rejection by users make it difficult to implement the health actions. This research emphasizes the limitations expressed by the health agents, and points towards the necessity of an evolving discussion of this theme, seeking strategies that enable the consolidation of community health principles.
\end{abstract}

Key words: Primary Health Care; Community Health Services; Delivery of Health Care.

\section{RESUMEN}

El presente estudio, cualitativo, objetivó conocer las dificultades sentidas por los Agentes Comunitarios de Salud (ACS) en ejercicio de la práctica diaria de la asistencia. Los datos fueron colectados por medio de entrevista semi estructurada con doce ACS de cuatro unidades básicas de salud de un municipio del estado de São Paulo, Brasil. A partir de los discursos se constató que la carencia de acciones resolutivas en los servicios de salud, existe sobrecarga en el hemisferio responsable por el equipo y el rechazo de los usuarios al atendimiento son factores que dificultan a ejecución de las acciones de la salud. Esa pesquisa afirma las limitaciones manifestadas por los participantes y apuntan la importancia de exploración de esa temática, buscando estrategias capaces de posibilitar la consolidación de los principios del SUS.

Palabras clave: Atención Primaria a Salud; Servicios de Salud Comunitaria; Asistencia a Salud. 


\section{INTRODUÇÃO}

No cenário de reformulação da assistência básica de saúde no Brasil, surgem os Programas de Agentes Comunitários de Saúde (PACS) e Saúde da Família (PSF), distinguindo-se do modelo tradicional com ênfase ao cuidado no aspecto biológico e na atenção centrada no indivíduo. Identificados como modelos inovadores, tais programas direcionam as suas ações ampliando o olhar para as questões da coletividade, no enfoque à saúde e aos fatores que a determinam.

Dessa forma, as duas estratégias estabeleceram desde o início da implantação, a inserção de Agentes Comunitários de Saúde (ACS), contribuindo para que as atribuições e as responsabilidades determinadas à Atenção Básica sejam executadas, de modo a permitir que os serviços de saúde atinjam a efetiva mudança na própria organização, com a melhoria da qualidade da assistência prestada.

Os ACS constituem-se em profissionais ativos para motivar a população e promover a melhoria de sua capacidade quanto aos cuidados com a saúde. Desse modo, transformam-se em atores imprescindíveis para as ações que envolvem o desenvolvimento psíquico, físico, econômico, político e social da população. Tal profissão foi regulamentada em 10 de julho 2002, com a lei 10.507, estabelecendo que os ACS sejam responsáveis pelo acompanhamento de 750 pessoas determinadas de acordo com a área de abrangência da Unidade de Saúde ${ }^{(1-2)}$.

No entanto, o trabalho dos ACS tem sido considerado atividade de uma carga excessiva, devido às distorções ocorridas por falta de uma clara delimitação de suas atribuições, de modo que ele é indevidamente responsabilizado sozinho pela consolidação do $S U S^{(3)}$.

Nessa mesma perspectiva, os ACS podem apresentar, com mais frequência, sintomas de estresse em relação aos demais membros da equipe, pelo fato de atuarem na criação de vínculos com a comunidade que assistem, sem terem recebido formação adequada e treinamento específico para o enfrentamento de possíveis dificuldades encontradas na relação estabelecida com o usuário ${ }^{(4)}$.

Desta forma, os ACS encontram-se em diferente situação relativamente aos outros membros da equipe de saúde, pois enquanto o médico, o enfermeiro, o auxiliar de enfermagem estão quase todo o tempo sob certa proteção da Unidade Básica de Saúde (UBS), os ACS estão nas ruas, expostos às várias situações, em nome da UBS, em ocorrências imprevistas, acolhidos em alguns momentos, mas em outros, expostos a circunstâncias conflitantes, podendo até enfrentar a estranheza da população $o^{(5)}$.

Pode-se enfatizar que o trabalho dos ACS, desenvolvido principalmente em área urbana, traz novos desafios, o que implica a necessidade de estudos mais abrangentes a respeito desta peculiaridade. Isso pode contribuir para melhor entendimento do significado do trabalho do ACS na perspectiva do Sistema Único de Saúde (SUS), com efeitos benéficos nas discussões sobre o próprio processo de trabalho. Além disso, as dificuldades encontradas em área urbana ultrapassam o campo da saúde e requerem uma ação intersetorial mais efetiva, devido aos problemas e agravos relacionados à violência, ao desemprego, à fome, e a outros fatores.

Outro aspecto relevante a respeito do trabalho dos ACS é referente aos limites de atuação que muitas vezes é determinado pelas políticas locais ou pelo fato de a família ou indivíduo assistido não se comprometer em cuidar de seu próprio estado de saúde ou de um ente familiar. Esse comportamento de transferência dos problemas de saúde para os profissionais, principalmente para os ACS, que estão a todo tempo em contato com a comunidade, leva a dificultar as ações, pois essa categoria profissional pode não conseguir a efetivação das propostas pretendidas de prevenção e promoção da saúde.

Os ACS estão direcionados e orientados para a execução de suas ações, conforme portarias editadas pelo Ministério da Saúde. Muitas vezes, como é permitido adaptação de acordo com a realidade local, esses profissionais carregam uma gama de atribuições muito mais extensas do que a pertinente na proposta dos programas PACS e PSF. Atente-se, ainda, para o fato de que esta profissão não é subsidiada por nenhum conselho ou sindicato próprio que exija algumas normatizações para a regulamentação, como é o caso dos outros profissionais da área da saúde.

A consideração das questões apresentadas acerca dos ACS leva-nos a refletir sobre esses profissionais atuantes nos serviços de saúde e na reorganização da prática sanitária vigente. Portanto este estudo, que é parte de uma pesquisa mais ampla, teve, como objetivo, conhecer as dificuldades sentidas pelos ACS no exercício da prática do cotidiano da assistência.

\section{MÉTODO}

O estudo, de natureza qualitativa, foi realizado em um município da região noroeste do estado de São Paulo, que possui uma população de 70.554 habitantes. A implantação do PACS ocorreu no ano de 2000, ocasião em que foram contratados, de início, 35 ACS, atuando nas regiões periféricas da cidade. Em junho de 2002, com a integração do PACS ao Programa de Combate à Dengue, considerou-se necessário ampliar o número de ACS no município, e, desta forma, o programa passou a contar com 67 profissionais, prevalecendo esse número até novembro de 2006. A partir de dezembro desse ano, devido à necessidade de ampliação e de extensão de cobertura, o programa passou a ter 112 ACS, distribuídos em todo o município e alocados nas cinco UBS.

No período de coleta de dados, a cobertura do programa em todo o município, ou seja, na área de atuação das cinco equipes, correspondia, aproximadamente, a 1.650.5 famílias cadastradas, num total de 52.433. pessoas, com cobertura de $75,4 \%$ da população.

Como critério para escolha dos participantes, foi estabelecido que os possíveis sujeitos deveriam ter acima de um ano de tempo de serviço junto ao PACS. Após o convite, aguardamos a manifestação voluntária dos interessados em participar da pesquisa, iniciamos as entrevistas ouvindo dois a três ACS de cada equipe e seguimos o critério de saturação preconizado por Minayo ${ }^{(6)}$. Desse modo, foram entrevistados 12 ACS, que se encontravam inseridos nas equipes alocadas nas UBS do município. 
A pesquisa teve aprovação do Comitê de Ética em Pesquisa da Faculdade de Medicina de Botucatu Unesp (OF.626/2006). Foi esclarecido aos possíveis participantes o propósito do estudo em questão e, a partir da anuência de cada participante com assinatura do Termo de Consentimento, realizou-se a entrevista na respectiva UBS de cada sujeito. Para essa fase utilizamos o gravador, iniciamos com a coleta dos dados de identificação de cada participante, e a seguir, recorremos à entrevista semiestruturada que ao mesmo tempo em que permite a livre percepção de cada pessoa acerca do vivido, permite que o pesquisador formule questionamento focado no interesse da investigação ${ }^{(6)}$. Nessa perspectiva, foi interrogado: Qual a dificuldade sentida por você para executar sua prática cotidiana? A fase de coleta de material de análise foi efetivada no período de abril a junho de 2007 e após a transcrição das entrevistas, foi utilizada a leitura flutuante ${ }^{(6)}$. O material advindo dos discursos produzidos mostrou-se rico em significados, possibilitando o cumprimento do objetivo proposto. Desse modo, recorreu-se à análise temática ${ }^{(7)} \mathrm{e}$, a partir desse procedimento, foi possível apreender as seguintes categorias: a) a carência de ações resolutivas na prática dos serviços, b) a sobrecarga do enfermeiro e c) a rejeição sentida pelos ACS. Essas serão discutidas a seguir.

\section{APRESENTAÇÃO E ANÁLISE DOS DADOS}

\section{Características dos sujeitos da pesquisa}

Todos os sujeitos da pesquisa são do sexo feminino, o que pode ser justificado pelo forte predomínio de ACS deste sexo nas equipes do local onde foi realizado o estudo.

Quanto à faixa etária, observou-se uma variação entre 26 e 56 anos, com maior concentração na faixa etária entre 40 a 47 anos. Ao avaliar o aspecto relacionado ao nível de escolaridade, dez sujeitos possuem o ensino médio completo e dois possuem nível superior.

Vê-se que a maioria das ACS possuem cinco anos ou mais de experiência, o que contribuiu para o enriquecimento dos conteúdos das falas. Desse modo, a partir da apreensão dos temas, foi possível estabelecer as categorias de análise: a carência de ações resolutivas na prática dos serviços, a sobrecarga do enfermeiro e a rejeição sentida pelos ACS, que serão tratadas a seguir.

\section{A. A carência de ações resolutivas no cotidiano dos serviços}

Os discursos demonstraram que os ACS sentem carência de ações resolutivas e de respaldo por parte dos profissionais da UBS. Isso foi relatado como fator negativo e impeditivo para o desenvolvimento do trabalho da categoria, destacando-se os problemas relacionados ao mau atendimento e ao deficit na oferta de serviços, conforme podemos verificar nas palavras textuais das entrevistas:

A falta de respaldo que eu encontro junto aos profissionais de saúde da UBS, porque a gente faz o trabalho casa a casa e quando eles vêm para UBS eles encontram dificuldade de atendimento, a falta de educação, a falta de vaga, são maltratados às vezes por profissionais de saúde como médico. Então esbarra nisso o meu trabalho. Dificuldade... (ACS 1)

E também a dificuldade é no balcão, o mau atendimento. As pessoas não sabem explicar, orientar o paciente direito. O paciente já vem com problema, chega aqui, toma uma resposta que, coitado, sai chateado. (ACS 2)

Quanto ao aspecto referente ao atendimento dos outros profissionais, fica evidente que os ACS compreendem haver divergências quanto às orientações e informações fornecidas por eles durante as visitas domiciliares. Eles mencionam a importância do acolhimento, do vínculo e da humanização nos serviços e correlacionam a ausência dessas práticas no atendimento dos demais profissionais da UBS, com a dificuldade na efetivação das suas ações. Na ótica dos ACS, o aspecto propulsor desse atendimento deficitário está vinculado ao despreparo desses profissionais no atendimento, principalmente, na entrada da UBS, ou seja, na recepção, onde é feito o primeiro contado do usuário com o serviço.

Na perspectiva da integralidade, conforme afirma Cecílio ${ }^{(8)}$, a equipe de saúde deve-se empenhar em traduzir e atender as necessidades de saúde dos indivíduos. Para tal, exigem-se comportamentos de escuta e vínculo por parte de todos os profissionais para com os usuários que acessam os serviços de saúde.

Assim, as Unidades de Saúde da Família estão organizadas para apoiar os profissionais de saúde, pois utilizam o trabalho em equipe como estratégia de organização do trabalho. Situação contrária a essa é encontrada nos serviços cujo modelo de assistência à saúde ainda pautado no tradicional ${ }^{(9)}$.

De acordo com os elementos apresentados, pode-se observar a ênfase que é dada pelos ACS ao aspecto relacional, quando referem que, muitas vezes, os profissionais são pouco atentos às necessidades que a demanda requer, além de apresentarem comportamentos hostis para com a população.

Para os sujeitos ouvidos, essas ocorrências são as responsáveis pela descontinuidade do trabalho, culminando com a diminuição da credibilidade do usuário no atendimento da UBS. Desse modo, quando o usuário, mediante o estímulo e encaminhamento dado pelos ACS, procura os serviços e não consegue acessá-lo, seja pela falta de vaga, pelo mau atendimento ou pela falta do profissional, passa a ter desconfiança no trabalho de toda a equipe.

Também podemos ressaltar que os ACS, frequentemente, chamam para si toda a responsabilidade do desdobramento da assistência. Os relatos revelam situações em que estes se colocam diante do usuário como facilitadores do acesso e, ao mesmo tempo, responsáveis pela falta do exercício ou efetivação desse direito.

E aí ele veio na unidade... ele também não se lembrou de chamar por mim, nada, mas aí meio que se recusaram a verificar a pressão dele naquela hora e ele morava no Lins V. Então é longe, só o fato da distância de vir até aqui... Então eu acho que a maior dificuldade, além da aceitação, é o respaldo. Aí eu voltei lá e ele falou: - Ah, eu não vou mais não! (ACS 9) 
Às vezes, desanima também quando, você traz o problema para cá e fica parado. Aí dá vontade de desistir. Porque eu acho que o meu trabalho não está sendo bem realizado. Então eu chego aqui, trago algum problema e não dá para resolver. Nossa! Isso para mim... Eu não tenho cara... eu não tenho cara de voltar na casa do morador e falar que não tem jeito, que não deu em nada. (ACS 12)

Em um estudo realizado, a partir da opinião de usuários a respeito do acesso e do acolhimento em unidades de saúde, foi constatado que os principais fatores valorizados por eles estão relacionados ao desempenho profissional de quem presta o atendimento, como também ao vínculo do usuário com o serviço de saúde, sendo, esses, essenciais para a resolubilidade e a satisfação de seus anseios ${ }^{(10)}$.

A carência de respaldo também foi mencionada pelos sujeitos desse estudo, no âmbito da intersetorialidade, ficando evidenciada a busca pela solução dos problemas detectados na comunidade. Nesse aspecto, os ACS procuram utilizar todos os meios disponíveis para conseguir amenizar o sofrimento e a angústia dos indivíduos, aspirações muitas vezes até oníricas, o que pode conduzir ao sentimento de impotência por não conseguirem solucionar os problemas existentes na micro área.

Assim, o processo de operacionalização das ações intersetoriais na Estratégia Saúde da Família pode ser considerado complexo e ainda em construção, entretanto, as dificuldades, estão ligadas a superação das hierarquias institucionais e das relações de poder existentes entre as corporações profissionais, setores, políticas e segmentos sociais ${ }^{(11)}$.

Até certo ponto a gente consegue caminhar, depois a gente é barrado, porque dali para frente não tem o que fazer e como fazer e às vezes fica parado. O que a gente começa e precisa assim de outras Secretarias, de outras, para poder funcionar, para poder ir para frente o nosso trabalho... Muitas vezes não acontece isso... Às vezes a pessoa que precisa de um médico, vamos supor assim, que precisa de uma especialidade, demora bastante, é complicado... A gente vê o sofrimento das pessoas, o quanto é duro, vai, volta, vai, volta. A gente fica... Eu fico meio deprimida, porque por não poder ajudar mais. Porque são obstáculos que às vezes não tem fim, não tem, não dá para ir. A gente não tem pernas para ir até lá. $A$ gente não pode fazer. Sem solução o problema. (ACS 4)

Existe uma correlação entre a inoperância do sistema frente às demandas da população e a conquista da credibilidade das famílias para com os ACS. Os sujeitos ouvidos relataram que mediante situações que explicitam a insuficiência de recursos do sistema de saúde como carência de vagas, pouca resolubilidade; não conseguem assumir a real situação ao estarem frente à população que requer atendimento. Tal experiência pode ser sentida como penosa para cada sujeito. Portanto, essa falha no sistema de referência e contra-referência, faz os ACS vivenciarem situações de constrangimento, refletindo-se em sofrimento psíquico ao executarem seu trabalho ${ }^{(12)}$.

Deste modo, os ACS caracterizam seu trabalho como difícil, pois o veem com possibilidades de ação limitada. Eles percebem que fazem parte de uma equipe, importante no convívio diário e capaz de encontrar alternativas e soluções para atender as necessidades das famílias ${ }^{(13)}$. Assim, constroem uma idéia de onipotência diante da comunidade, idealizando qualidade, transformação, resultado, humanização, resolubilidade, poder e doação, desconsiderando a viabilidade dos outros recursos necessários, além, de seus próprios ${ }^{(5)}$.

Até o remédio! Que a gente conhece a população, principalmente ali, onde a gente está todo o mês, a gente sabe que a pessoa é pobre, que a pessoa não tem condição de comprar o remédio. O difícil é até para pedir para prefeitura, para ajudar. Olha, ela é, deficiente, está na cadeira de rodas, e ela precisa tomar um determinado remédio para dor, e é difícil isso. É uma coisa que deixa a gente bem triste, sabe? A pessoa está precisando, e às vezes a gente vê até um que pode, conseguindo o que a agente comunitária luta e não consegue. (ACS 3)

Um idoso que a gente encaminha para cá, muitas vezes ele não é bem atendido... A gente coloca a nossa cara lá na rua e então tudo de mau que acontece nós somos os primeiros a estar ali ouvindo as coisas, as primeiras queixas. O mau atendimento, uma má acolhida, nós somos os primeiros a estar ouvindo essas queixas. E... são essas dificuldades, não tem retorno do nosso trabalho. (ACS 6)

Por estarem na comunidade com as famílias estão mais predispostos ao enfrentamento das reclamações em relação ao serviço, e são colocados pelos profissionais de saúde, por usuários e por si próprios na posição de mediadores para o destempero que ocorre nas relações entre a população e a UBS.

Portanto, a dificuldade dos serviços em obter a integralidade do cuidado e a articulação dos diferentes níveis de atenção, acompanhada das fragilidades do sistema de referência e contra-referência, ocasionam interferências no trabalho dos ACS, que se deslocam aos domicílios e são questionados em relação às necessidades não atendidas ${ }^{(9)}$.

Por outro lado, os sujeitos demonstram que, mesmo com as dificuldades enfrentadas na composição do trabalho, ainda existe a expectativa de que o SUS, representado em âmbito local pelas UBS, seja, de fato, um sistema de saúde humanitário e resolutivo, proporcionando a prevenção e o tratamento das enfermidades da população.

Eu tenho uma mesma família que a moça, ela está numa depressão profunda, e ela está tratando pelo convênio, mas eu falei para ela: você não quer ir para o SUS? Para ver se tem um jeito, porque já faz vários tempos que ela está assim. E ela está no fundo do poço mesmo. Eu falei: quem sabe, você no SUS você vai ter. (ACS 7)

Tanto é que assim, esse mês mesmo eu mandei acho que quinze mulheres para passar no ginecologista. Sabe aquela coisa assim, que tem mais acesso, você não precisa ficar pegando fila, de vez em quando a gente pode marcar. Mas 
assim, elas estão vindo mais. Então está assim, mais tranqüilo. Aos poucos está dando para mudar, mesmo porque $o$ atendimento aqui está melhorando muito. (ACS 11)

Denota-se que os sujeitos ouvidos acreditam no próprio trabalho, defendem plenamente os direitos dos usuários em relação ao acesso aos serviços de saúde e quando este é conquistado mencionam a melhora do sistema. Em outras palavras, veem o acesso aos serviços de saúde como um fator positivo, indicativo da melhoria do sistema.

\section{B. A sobrecarga do enfermeiro}

A carga excessiva de trabalho destinada ao enfermeiro foi mencionada como fator que dificulta aos ACS, executarem a prática diária. Ao relatarem essa dificuldade, os sujeitos a relacionam à falta de recursos humanos, destacando que apenas um profissional enfermeiro não é suficiente para atender às demandas que são trazidas pelos ACS, associadas às outras tantas solicitações da UBS. Para os sujeitos, a dificuldade do enfermeiro em corresponder às muitas expectativas gera insatisfações, podendo estar relacionada à perda da credibilidade da família para com os ACS.

São muitos acamados para enfermeira cuidar e não dá tempo. Então assim, é isso daí o porém. Aí, é não veio, já deu o mês, não é que são muitos não dá mesmo para ela dar conta. Para uma enfermeira só não dá. (ACS 2)

É indiscutível que a questão das muitas atribuições com as quais o enfermeiro se depara ao desenvolver suas funções, mereça reconhecimento e consideração. Porém, embora os participantes de nosso estudo tenham expressado solidariedade, compreensão para com o enfermeiro e às vezes, até tenham tentado explicar a ausência desse profissional, enfatizam a carência e a necessidade que sentem de maior contato, supervisão, tempo de escuta, discussão de fatos ocorridos na imprevisibilidade característica do tipo de atividade que executam. Tal fato nos leva a refletir que tal carência pode ser mais um fator de sofrimento no trabalho.

Eu sei que para ela é difícil, que para ela aqui tem muito mais serviço, não dá para ela fazer visita para todos os pacientes... (ACS 5)

Todavia o oposto a esta situação, ou seja, quando o enfermeiro está presente nas visitas domiciliares, é relatado pelos sujeitos como fator de conquista, sugerindo que inúmeras expectativas são depositadas nas visitas do enfermeiro, por ser este um profissional técnico e representar o serviço de saúde. Portando, é esperado que ele possa corresponder aos anseios da família, levando o conhecimento técnico específico e buscando resolver os problemas encontrados nas mais diversas situações.

A importância da moça, da enfermeira. Olha na hora que a gente chega com a enfermeira numa casa, é difícil você não ouvir: um anjo chegou, de tão carente que a população é, tantos problemas. (ACS 3)
A sobrecarga de tarefas da enfermeira é apontada pelos ACS como o principal motivo da falta de supervisão. Tal ação é considerada como uma atividade importante para discussão das adversidades encontradas no cotidiano do trabalho, como também representa um espaço para reflexão, em que a enfermeira pode avaliar a necessidade de informação, capacitação e educação permanente ${ }^{(4)}$.

No contexto deste estudo, o enfermeiro supervisor dos ACS está inserido em uma UBS, cumprindo atribuições específicas que Ihe foram destinadas, às vezes, tomado pela rotina da Unidade, principalmente quando há falta do enfermeiro responsável pela atividade. Além disso, é responsável por um grupo numeroso de ACS, com média de 20 a 30 por equipe e, consequentemente, um número significativo de famílias.

Entretanto, ao executarem as ações que lhes foram atribuídas, os ACS enfrentam contratempos e diversidades que precisam ser compartilhadas e canalizadas ao enfermeiro, isto com o objetivo de buscar as referências necessárias para a solução dos problemas. Paralelamente, o enfermeiro pode estar inserido em atividades assistenciais e gerenciais que demandam grande parte do seu tempo para essas ações. Então, é possível justificar a queixa apresentada pelos sujeitos, a partir das inúmeras demandas conferidas ao enfermeiro, o que dificulta o estabelecimento de planejamento sistematizado e ordenado para contemplar as necessidades sentidas pelos ACS. Além disso, a queixa maior parece estar relacionada à dificuldade do enfermeiro em executar as visitas domiciliares, principalmente aos usuários dependentes de cuidados, os acamados. É possível que, nestes casos, os sujeitos sofram algum tipo de pressão dos familiares ou cuidadores que se responsabilizam pelo cuidado domiciliar desses pacientes, uma vez que a visita do enfermeiro tem caráter instrutivo, cujo objetivo é tranquilizá-los e orientando-os tecnicamente sobre os cuidados necessários e emergentes.

\section{A rejeição sentida pelos ACS}

Ao relatarem as dificuldades encontradas na execução da prática diária de trabalho, um elemento desencadeador do insucesso aparece atrelado à postura de alguns usuários em não aceitarem o trabalho dos ACS. Para os sujeitos, essa questão se deve ao fato de os usuários não entenderem o objetivo do trabalho e o delineamento das propostas geradoras das ações de promoção da saúde e de prevenção de doenças. Os discursos sugerem que esse fato pode estar relacionado à resistência dos usuários às estratégias inovadoras de saúde, bem como à falta de tempo em receber os ACS no domicílio. Nos relatos, podemos perceber o sofrimento vivido pelos ACS pela rejeição do usuário ao seu trabalho.

Estou com uma gestante que quer ver o capeta, mas não quer me ver... Ela não quer passar os dados. Vou na casa dela e ela não me atende... Para mim parece que o meu serviço não está valendo nada... Ontem eu passei na casa dela o filho dela falou para mim que estava de oito meses já... e eu a vi no primeiro mês, não vi mais! (ACS 5)

Para os sujeitos, a aceitação dos usuários pelo seu real trabalho, tem significado profundo no que diz respeito à 
gratificação, e quando o reconhecimento não acontece isto pode contribuir para a geração de sofrimento. É evidente, nos discursos produzidos, o comprometimento e a dedicação exaustiva em relação aos usuários, na tentativa de sensibilizá-los para as atividades realizadas. Por outro lado, parece existir, por parte dos sujeitos ouvidos, certa idealização do paciente, associada à idéia de que a experiência de anos de trabalho não permite aceitar a rejeição e a reprova de suas práticas. Os discursos revelam-se enfáticos ao explicitarem que a atitude dos usuários de não reconhecimento do trabalho executado pelos ACS é inadmissível para o cumprimento de suas metas. Estes também não se conformam em não conseguirem acessar esse ou aquele domicílio ou família.

É a aceitação da pessoa. Ela querer te atender. Porque eu encontro isso na minha área em algumas casas, assim que não querem me atender, mesmo depois de tanto tempo. Quatro anos e pouco... e a pessoa não quer te receber... ou fecha toda casa para te atender só no quintal, entendeu? Então essa é a maior dificuldade. Você tem que ficar pedindo todo o mês para entrar, entendeu?... E eu tenho gente, é incrível! Que abre o vitrô, te olha, fecha o vitrô e não te atende. Isso joga você lá embaixo, autoestima, você fica frustrada, você acha que o seu trabalho... além de não estar sendo reconhecido... não tem um porquê.... Isso é complicado. Isso te... baqueia bastante, pelo menos para mim. (ACS 8)

A maioria dos ACS tem dificuldades em manter relações interpessoais com os usuários e esse fato ocorre, com maior frequência, com os moradores de maior poder aquisitivo, os quais dificultam as ações dos ACS na família ${ }^{(14)}$.

Outro ponto a ser discutido em virtude da aceitação do usuário ao trabalho dos ACS está relacionado às questões socioeconômicas das famílias bem como aos equipamentos de saúde acessados por eles. No relato abaixo apresentado, evidencia-se uma negação constante quando os ACS têm que adentrar o ambiente domiciliar. A família detentora de planos privados justifica a negativa de aceitação do SUS, dizendo ter acesso aos planos de saúde e não precisar dos serviços prestados pelos ACS.

Ah... além da aceitação, dependendo do morador, que não são todos que tem boa aceitação, que assim, eu encontro muito assim, que a pessoa acha que ela tem convênio, ela não precisa ser cadastrada, principalmente como gestante, é a maior dificuldade que eu tenho é de cadastrar gestante que tem convênio, que ela acha que ela não vai precisar da unidade. Eu vou todo o mês no meu médico, então eu não vou precisar. (ACS 9)

A maior barreira é também em relação às pessoas idosas. Assim, principalmente as que vivem sozinhas. Não gostam de abrir a porta para a gente, tem medo de ser um ladrão, não conhece o trabalho. Até você explicar o que é o seu trabalho, ele entender, leva tempo. Eu acho que essa é a maior barreira. (ACS 10)
Assim, fica evidenciado, que os sujeitos ouvidos possuem um bom entendimento sobre as diretrizes do SUS, principalmente sobre universalidade e integralidade. De modo que, baseando-se nessa perspectiva, tentam estimular o usuário a compreender a importância do próprio trabalho na comunidade. No entanto demonstram sentirem as consequências dos conceitos que circulam na sociedade, muitas vezes equivocados, acerca dos serviços de saúde oferecidos, associados à desinformação da comunidade, acerca do desempenho executado pelo ACS, somados à idéia de que os ACS são apenas facilitadores de acesso à unidade de saúde.

Ressaltando a especificidade do trabalho do ACS, Queirós e Lima ${ }^{(15)}$ consideram que há momentos de tensões no desempenho de seu papel de interlocução com a comunidade, ao se posicionarem como parte integrante do serviço, este profissional é visto como membro do governo na comunidade e nas situações em que este representa a comunidade em seu serviço, pois apresenta-se como um articulador dos problemas e soluções, e em outros momentos aparece como tensionador das reivindicações populares.

Com relação à prática assistencial do ACS, também foi evidenciado nos discursos que, em algumas situações, as informações emitidas não são absorvidas pelos usuários, ficando evidente a dificuldade em atingir mudanças de hábito e de comportamentos no que diz respeito ao cuidado com a prevenção das doenças e a promoção da saúde.

Desta forma, os ACS utilizam estratégias para executar ações de educação à saúde, já que percebem várias formas de resistências por parte da população, sendo essas manifestadas quando não são adotados os comportamentos propostos (alimentares, higiênicos e outros) ou até no caso de oposição deliberada, demonstrada pela recusa em receber membros da equipe no domicílio ${ }^{(16)}$.

Bom, a maior dificuldade é você tentar educar o morador... Com essa epidemia da dengue que está tendo, é uma coisa triste, porque mesmo na nossa micro-área que você passa todo o mês, o mês que a gente entra olha. Agora como nós fizemos o arrastão, nós só estamos orientando... porque hoje eles botam reciclados e a gente vai para o arrastão tiramos tudo, e a gente volta, está a mesma coisa. (ACS 3)

Refletindo sobre o desapontamento dos ACS, ao não atingirem seus objetivos com as ações pertinentes à educação em saúde, percebemos, nos relatos, que, muito embora eles considerem importantes as referidas ações, encontram obstáculos em relação à resistência na mudança de hábito por parte da comunidade.

Desta forma, a resistência e indiferença dos usuários em aceitarem e seguirem suas orientações, principalmente em relação às mudanças de hábito referentes à higiene, é considerado como fator de sobrecarga dos ACS. Ao assumir o papel de profissional de saúde, os ACS tendem a carregar uma idealização da verdade absoluta, não considerando o quanto é complexa a tarefa de mudança de hábito da população, geralmente relacionada a outras práticas e saberes ${ }^{(4)}$.

Neste sentido, pode-se considerar assimétrica, a relação 
entre profissionais e usuários, sendo estes, considerados indivíduos carentes de informações em saúde, enquanto os profissionais sentem-se detentores do saber técnico-científico. No entanto, para a efetiva participação popular é preciso um envolvimento de ambas as partes, por meio de diálogo entre os saberes, compartilhando vivências e práticas cotidianas ${ }^{(17)}$.

Mediante as questões expostas, na ótica dos sujeitos ouvidos, a rejeição dos usuários frente ao trabalho desempenhado por esses profissionais limita o exercício do próprio papel, sendo que tal rejeição pode se constituir em fatores de desestímulo ou de frustração, afetando o comprometimento com a fortificação do elo entre os serviços de saúde e os usuários.

\section{CONSIDERAÇÕES FINAIS}

Pensar no trabalho do ACS traz inquietações, anseios, dúvidas e conflitos que envolvem questões sensíveis ao nosso entendimento, como, por exemplo, o fato de esses profissionais vivenciarem, no cotidiano do trabalho, situações-limite como pobreza, desigualdade social, violência, abandono, doença. Tudo isso, somado à situação dos ACS de serem ao mesmo tempo, representantes do serviço e moradores da comunidade na qual trabalham.

O presente estudo evidencia que os ACS são capazes de romper barreiras sociais, econômicas e até éticas, embora não esteja estabelecido nenhum código para a profissão. No entanto esse ímpeto na prática da assistência, também pode favorecer os sentimentos de frustração e de angústia, conforme foi demonstrado nos relatos ouvidos. Vê-se que a busca pela solução dos problemas encontrados na comunidade faz com que os ACS se confrontem com a carência de ações resolutivas, seja de forma intersetorial ou no próprio serviço de saúde.

Um elemento digno de nota é a maneira pela qual os ACS veem o enfermeiro, considerando esse profissional um facilitador que articula as relações dos usuários com os demais membros da equipe da UBS e até com os próprios ACS. Na perspectiva dos entrevistados, o saber clínico disposto pelo enfermeiro consegue corresponder a uma parte das necessidades de saúde da comunidade, o que conforta os ACS frente ao sofrimento vivido pelas famílias. No entanto, é visível a carência e a necessidade que sentem de maior contato com o profissional enfermeiro.

Por outro lado, a dificuldade do usuário em acessar os serviços é vista por nossos sujeitos, como aspecto que dificulta o desenvolvimento do trabalho e torna-se fator negativo para o dia a dia dos ACS, uma vez que os participantes ouvidos revelam ter bom entendimento e compreensão sobre os princípios e diretrizes do Sistema Único de Saúde. Ressalte-se, porém que dada a versatilidade desses profissionais, eles detêm estratégias próprias para vencer as dificuldades apresentadas nas várias situações vivenciadas.

As questões apresentadas acerca dos ACS impulsionam reflexões sobre a importância de sua prática para solidificação da integralidade da assistência e reestruturação dos modelos vigentes nos serviços de saúde.

Todavia é necessário considerar que esses profissionais também são integrantes de outras relações pessoais e sociais básicas, fundamentais para a manutenção do equilíbrio do estado emocional frente ao trabalho. Vê-se que cada um busca respostas, da forma como pode, para dar conta das soluções nem sempre encontradas nos manuais técnicos do Ministério da Saúde, nos protocolos dos serviços, nas coordenações municipais ou nas recomendações dos gestores. Desse modo, ressalta-se que a vivência, a experiência de cada ACS conduz a caminhos positivos e/ou de frustração do trabalho, sendo que seus parceiros, muitas vezes são encontrados nas igrejas, nas associações de bairro, ou em outros espaços comunitários.

Dado o exposto, faz-se necessário desenvolver outros estudos que contemplem tal temática para a perpetuação da pesquisa sobre o assunto. Isso pode impulsionar à busca de estratégias capazes de possibilitar a estratégica e desejada consolidação dos princípios do SUS, sobretudo no que se refere aos aspectos abordados na universalização, integralidade e equidade.

\section{REFERÊNCIAS}

1. Brasil. Ministério da Saúde. Secretaria de Atenção à Saúde. Portaria n 648/GM, de 28 de março de 2006. Aprova a Política Nacional de Atenção Básica [portaria na internet]. Diário Oficial da União 2006 [acesso em 21 set 2006]. Disponível em: http://drt2004.saude.gov.br/dab/ legislação.php

2. Brasil. Ministério da Saúde. Legislação do SUS. Lei 10.507, de 10 de julho de 2002. Cria a Profissão de Agente comunitário de Saúde e dá outras providências [legislação na internet]. Diário Oficial da União 1990 [acesso em 21 set 2006]. Disponível em: http://dtr2004.saude.gov.br/ legislação.php

3. Tomaz JBC. O agente comunitário de saúde não deve ser um "super-herói". Interface Comunic Saúde Educ 2002;6(10):75-94.
4. Wai MFP. O trabalho do Agente Comunitário de Saúde na Estratégia Saúde da Família: fatores de sobrecarga e mecanismos de enfrentamento. Ribeirão Preto. Dissertação [Mestrado em Enfermagem psiquiátrica] -Escola de Enfermagem da USP; 2007.

5. Martines WRV. Compreendendo o processo de sofrimento no trabalho do Agente Comunitário de Saúde no Programa Saúde da Família. São Paulo. Dissertação [Mestrado em Ciências da Saúde] -Escola de Enfermagem da USP; 2005.

6. Minayo MCS. O desafio do conhecimento: pesquisa qualitativa em saúde. 9. ed. São Paulo: Hucitec; 2006.

7. Bardin L. A análise de conteúdo. Rio de Janeiro: Edições 70; 1994 
8. Cecilio LCO. As necessidades de saúde como conceito estruturante na luta pela integralidade e equidade na atenção em saúde. In: Pinheiro R, Mattos RA. Os sentidos da integralidade na atenção e no cuidado à saúde. 3. ed. Rio de Janeiro: ABRASCO/UERJ; 2001. p. 113-25.

9. Peres CRFB. O trabalho do agente comunitário de saúde no município de Marília - SP. Botucatu. Dissertação [Mestrado em Ciências da Saúde] -Faculdade de Medicina, Universidade Estadual Paulista; 2006.

10. Lima MADS, Ramos DD, Rosa RB, Nauderer TM, Davis R. Acesso e acolhimento em unidades de saúde na visão dos usuários. Acta Paul Enferm 2007;20(1):12-7.

11. Silva KL, Rodrigues AT. Ações intersetoriais para promoção da saúde na Estratégia Saúde da Família: experiências, desafios e possibilidades. Rev Bras Enferm 2010;63(5):762-9.

12. Jardim TA. Morar e trabalhar na comunidade: a realidade dos agentes comunitários de saúde. São Paulo. Dissertação [Mestrado em Ciências da Saúde] -Faculdade de Medicina da USP; 2007.
13. Lunardelo SR. O trabalho do agente comunitário de saúde nos núcleos de Saúde da Família em Ribeirão Preto - São Paulo. Ribeirão Preto. Dissertação [Mestrado em Ciências da Saúde] - Escola de Enfermagem da USP; 2004.

14. Meira RMMBP. O agente comunitário de saúde: convergências e divergências, na percepção dos próprios agentes, dos médicos, enfermeiros e usuários do serviço. Botucatu. Dissertação [Mestrado em Ciências da Saúde] -Faculdade de Medicina da Universidade Estadual Paulista; 2008.

15. Queirós AAL, Lima LP. A institucionalização do Agente Comunitário de Saúde. Trab Educ Saúde 2012;10(2):257-81.

16. Nunes MO, Trad LB, Almeida BA, Homem CR, Melo MCIC. O agente comunitário de saúde: construção da identidade desse personagem híbrido e polifônico. Cad Saúde Pública 2002;18(6): 1639-1646.

17. Costa GD, Cotta RMM, Ferreira MLSM, Reis JR, Franceschini SCC. Saúde da Família: desafios no processo de reorientação do modelo assistencial. Rev Bras Enferm 2009;62(1):113-118. 